\title{
The burden of chronic pain and the role of neurorehabilitation: consensus matters where evidence is lacking
}

This article was published in the following Dove Press journal:

Journal of Pain Research

4 January 2017

Number of times this article has been viewed

\author{
Stefano Tamburin' \\ Stefano Paolucci \\ Nicola Smania ${ }^{1,3}$ \\ Giorgio Sandrini $i^{4,5}$ \\ 'Department of Neurosciences, \\ Biomedicine and Movement \\ Sciences, University of Verona, \\ Verona, ${ }^{2}$ Santa Lucia Foundation, \\ IRCCS, Rome, ${ }^{3}$ Neuromotor and \\ Cognitive Rehabilitation Research \\ Centre, University of Verona, Verona, \\ ${ }^{4} \mathrm{C}$. Mondino National Institute \\ of Neurology Foundation, IRCCS, \\ ${ }^{5}$ Department of Brain and Behavioural \\ Sciences, University of Pavia, Pavia, \\ Italy
}

On behalf of the Italian Consensus Conference on Pain in Neurorehabilitation (ICCPN)

Correspondence: Stefano Tamburin Department of Neurosciences, Biomedicine and Movement Sciences, University of Verona, Piazzale Scuro 10, I-37I 34 Verona, Italy

Tel +39045 8124285

Fax +390458027276

Email stefano.tamburin@univr.it
Pain is one of the most common reasons for seeking medical attention. When chronic, it diminishes self-perceived health status, interferes with everyday activities, lowers productivity, and affects personal relationships. Persistent noncancer pain can also result in depressive symptoms. ${ }^{1}$ The prevalence of chronic pain ranges from $8 \%$ to $48 \%$ in the general population, with a weighted average prevalence of $22 \%$. $^{2}$ According to a systematic review of chronic noncancer pain in Europe, the 1-month prevalence of moderate-to-severe pain is estimated to be $19 \% .{ }^{1}$ A Canadian study documented that chronic pain is more prevalent among women $(16.5 \%-21.5 \%)$ and the elderly $(23.9 \%-31.3 \%)$, with women aged 65 years and older accounting for the majority of pain sufferers $(26.0 \%-34.2 \%) .{ }^{3}$ The prevalence of neuropathic pain, as defined in two general population surveys, ${ }^{4,5}$ was found to range between $3 \%$ and $18 \%$; the average prevalence was $7 \%$ when weighted by study size. ${ }^{2}$ In patients with comorbid illnesses, $15 \%$ of patients with diabetes mellitus report painful peripheral neuropathy, ${ }^{2} 19 \%-74 \%$ of stroke survivors suffer from poststroke pain, ${ }^{6}$ with a mean overall prevalence of $29.6 \%{ }^{7}$ Furthermore, the overall point prevalence of pain in multiple sclerosis is around $50 \%$, ${ }^{6}$ neuropathic pain affects $40 \%$ of patients with spinal cord injury, ${ }^{2,6}$ and up to $80 \%$ of Parkinson's disease patients report some type of pain. ${ }^{8}$

Chronic pain places a huge burden on all quality of life and daily living domains, including independence and self-management, personal relationships, sexual function, household chores, work, mobility, exercise, enjoyment, and sleep. In addition, it is also associated with reduced attention, cognitive symptoms, depressive mood, and anxiety. ${ }^{2,9}$ Patients with moderate-to-severe chronic pain require more physician visits and medications and spend more days in hospital, incurring costs 2-3 times higher than patients with no or mild pain. ${ }^{2,10}$ From a societal perspective, chronic pain reduces work productivity and labor market participation and increases absenteeism from work, resulting in costs $1.2-7.8$ times higher than in people without pain. ${ }^{2,9,11}$ It has been suggested that the mortality rate is higher for patients with chronic pain, ${ }^{2}$ but this finding was not confirmed after adjusting for potential confounders, such as lifestyle factors, physical activity, and smoking status. ${ }^{12}$

Correct diagnosis and adequate treatment of pain would not only benefit affected patients but also reduce health care utilization and related societal costs. ${ }^{2,11}$ Pain is common in the neurorehabilitation setting. Among the medical conditions requiring rehabilitation in the US, for example, low back pain and arthritis carry the highest 
economic and social costs of all painful syndromes. ${ }^{13}$ Despite the centrality of pain as a target of neurorehabilitation and as a factor potentially affecting treatment outcome, guidelines and consensus statements on pain management in this setting have long been lacking. ${ }^{14}$ To fill this knowledge gap, the Italian Consensus Conference on Pain in Neurorehabilitation (ICCPN) called together a panel of experts in neurology, (neuro)rehabilitation, and/or pain. ${ }^{14}$

There are no data from neurorehabilitation studies applying methods from evidence-based medicine (EBM) because of the difficulty in blinding investigators and patients to the intervention and the lack of standardization of physical therapy and rehabilitation procedures. Therefore, rather than conduct a systematic review of the literature, we took advantage of the consensus conference format since it offers a broad perspective that can be gained from multiple sources, including observational, case-control and other types of studies, expert opinion, randomized controlled trials (RCTs), meta-analyses, guidelines, and recommendations. ${ }^{14}$ The main limitation of a consensus conference is the potential arbitrariness of the conclusions; however, a large panel of experts from various fields of medicine may at least partially overcome any bias. The ICCPN full methods are reported in detail in a recently published methodological paper. ${ }^{14}$

The ICCPN task force comprised 27 working groups and included 128 experts from a wide range of specialties (neurology, physical medicine and rehabilitation, pain medicine, psychology, neurophysiology, pharmacology, physical therapy, orthopedics, gynecology, and urology), which reflected the multidisciplinary approach typical of neurorehabilitation. The literature search and the evaluation and scoring of the reviewed articles ${ }^{14}$ took several years to complete. The ICCPN recommendations have been recently published in open access format. ${ }^{6,8,15-19}$ The ICCPN yielded 252 recommendations, $32(12.7 \%)$ of which were scored as Grade A, 58 (23.0\%) as Grade B, 39 (15.5\%) as Grade C, and $27(10.7 \%)$ as Grade D. The majority of the recommendations $(96 / 252,38.1 \%)$ were based on expert opinion, in the absence of any consistent evidence, and were scored as a good practice point. Although most of the Grades A and B evidence came from studies in neurology, clinical neurophysiology, or pain therapy, it was still considered to be pertinent to neurorehabilitation. Many of the recommendations on physical therapies and exercise received low scores (D or good practice point). Taken together, they underscore the overall low quality of current EBM data on pain assessment and treatment in neurorehabilitation. This limitation notwithstanding, valuable lessons can be learned on how to design more robust and methodologically sound RCTs in this setting.

There is an emerging debate on how to improve the design of clinical trials to make their results more useful for the real-life clinical setting or a specific health care scenario. ${ }^{20}$ Researchers in neurorehabilitation should aim for a pragmatic design of their RCTs. Moreover, the efficacy of a multidisciplinary approach, which characterizes neurorehabilitation, relies on a combination of pharmacological treatments, physical and occupational therapy, and psychological interventions to be tested in pain conditions, such as the complex regional pain syndrome, where single interventions alone are poorly effective. ${ }^{19}$

Although patient-centered measures, such as quality of life scores, measures of degree of disability, and impact on daily living activities are common outcomes, quite disappointingly, the ICCPN found no strong evidence about which assessment scales should be used for evaluating patients with pain in neurorehabilitation. Further work is needed to better address this issue. Moreover, these outcomes should be incorporated in RCTs to explore whether they could serve as a better proxy for patient satisfaction than changes in pain intensity alone.

Until solid EBM data become available, the ICCPN recommendations may provide helpful guidance for improving pain assessment and treatment in the neurorehabilitation setting.

\section{Disclosure}

The authors report no conflicts of interest. This editorial represents the opinions of the authors, and has not been reviewed or prepared as part of any government agency or companies listed.

\section{References}

1. Reid KJ, Harker J, Bala MM, et al. Epidemiology of chronic non-cancer pain in Europe: narrative review of prevalence, pain treatments and pain impact. Curr Med Res Opin. 2011;27(2):449-462.

2. Andrew R, Derry S, Taylor RS, Straube S, Phillips CJ. The costs and consequences of adequately managed chronic non-cancer pain and chronic neuropathic pain. Pain Pract. 2014;14(1):79-94.

3. Reitsma ML, Tranmer JE, Buchanan DM, Vandenkerkhof EG. The prevalence of chronic pain and pain-related interference in the Canadian population from 1994 to 2008. Chronic Dis Inj Can. 2011;31(4):157-164.

4. Torrance N, Smith BH, Bennett MI, Lee AJ. The epidemiology of chronic pain of predominantly neuropathic origin. Results from a general population survey. J Pain. 2006;7(4):281-289.

5. Bouhassira D, Lanteri-Minet M, Attal N, Laurent B, Touboul C. Prevalence of chronic pain with neuropathic characteristics in the general population. Pain. 2008;136(3):380-387.

6. Paolucci S, Martinuzzi A, Scivoletto G, et al. Assessing and treating pain associated with stroke, multiple sclerosis, cerebral palsy, spinal cord injury and spasticity. Evidence and recommendations from the Italian Consensus Conference on Pain in Neurorehabilitation. Eur J Phys Rehabil Med. Epub August 31, 2016. 
7. Paolucci S, Iosa M, Toni D, et al. Prevalence and time course of post-stroke pain: a multicenter prospective hospital-based study. Pain Med. 2016; 17(5):924-930.

8. Bartolo M, Chiò A, Ferrari S, et al. Assessing and treating pain in movement disorders, amyotrophic lateral sclerosis, severe acquired brain injury, disorders of consciousness, dementia, oncology and neuroinfectivology. Evidence and recommendations from the Italian Consensus Conference on Pain in Neurorehabilitation. Eur J Phys Rehabil Med. Epub August 31, 2016.

9. Davis JA, Robinson RL, Le TK, Xie J. Incidence and impact of pain conditions and comorbid illnesses. J Pain Res. 2011;4:331-345.

10. Mehra M, Hill K, Nicholl D, Schadrack J. The burden of chronic low back pain with and without a neuropathic component: a healthcare resource use and cost analysis. J Med Econ. 2012;15(2): $245-252$

11. Langley P, Muller-Schwefe G, Nicolaou A, Liedgens H, Pergolizzi J, Varrassi G. The impact of pain on labor force participation, absenteeism and presenteeism in the European Union. JMed Econ. 2010;13(4): 662-672.

12. Åsberg AN, Heuch I, Hagen K. The mortality associated with chronic widespread musculoskeletal complaints: a systematic review of the literature. Musculoskeletal Care. Epub July 19, 2016.

13. Ma VY, Chan L, Carruthers KJ. Incidence, prevalence, costs, and impact on disability of common conditions requiring rehabilitation in the United States: stroke, spinal cord injury, traumatic brain injury, multiple sclerosis, osteoarthritis, rheumatoid arthritis, limb loss, and back pain. Arch Phys Med Rehabil. 2014;95(5):986-995.e1.
14. Tamburin S, Paolucci S, Magrinelli F, Musicco M, Sandrini G. The Italian Consensus Conference on Pain in Neurorehabilitation: rationale and methodology. J Pain Res. 2016;9:311-318.

15. Castelnuovo G, Giusti EM, Manzoni GM, et al. Psychological treatments and psychotherapies in the neurorehabilitation of pain: evidences and recommendations from the Italian Consensus Conference on Pain in Neurorehabilitation. Front Psychol. 2016;7:115.

16. Castelnuovo G, Giusti EM, Manzoni GM, et al. Psychological considerations in the assessment and treatment of pain in neurorehabilitation and psychological factors predictive of therapeutic response: evidence and recommendations from the Italian Consensus Conference on Pain in Neurorehabilitation. Front Psychol. 2016;7:468.

17. Porro CA, Sandrini G, Truini A, et al. Diagnosing and assessing pain in neurorehabilitation: from translational research to the clinical setting. Evidence and recommendations from the Italian Consensus conference on pain in neurorehabilitation. Eur JPhys Rehabil Med. 2016;52(5):717-729.

18. Aloisi AM, Berlincioni V, Torta R, et al. The role of gender, psychosocial factors and anthropological-cultural dimensions on pain in neurorehabilitation. Evidence and recommendations from the Italian Consensus Conference on Pain in Neurorehabilitation. Eur J Phys Rehabil Med. 2016;52(5):730-740.

19. Tamburin S, Lacerenza MR, Castelnuovo G, et al. Pharmacological and non-pharmacological strategies in the integrated treatment of pain in neurorehabilitation. Evidence and recommendations from the Italian Consensus Conference on Pain in Neurorehabilitation. Eur J Phys Rehabil Med. 2016;52(5):741-752.

20. Ford I, Norrie J. Pragmatic trials. NEngl J Med. 2016;375(5):454-463.

Dove Medical Press encourages responsible, free and frank academic debate. The content of the Journal of Pain Research 'Editorial' section does not necessarily represent the views of Dove Medical Press, its officers, agents, employees, related entities or the Journal of Pain Research editors. While all reasonable steps have been taken to confirm the content of each Editorial, Dove Medical Press accepts no liability in respect of the content of any Editorial, nor is it responsible for the content and accuracy of any Editorial.

\section{Journal of Pain Research}

\section{Publish your work in this journal}

The Journal of Pain Research is an international, peer reviewed, open access, online journal that welcomes laboratory and clinical findings in the fields of pain research and the prevention and management of pain. Original research, reviews, symposium reports, hypothesis formation and commentaries are all considered for publication.

\section{Dovepress}

The manuscript management system is completely online and includes a very quick and fair peer-review system, which is all easy to use. Visit http://www.dovepress.com/testimonials.php to read real quotes from published authors. 